\title{
MXene-Derived Quantum Dot@Gold Nanobones \\ Heterostructure-Based Electrochemiluminescence Sensor for \\ Triple-Negative Breast Cancer Diagnosis
}

Yixin $\mathrm{Nie}^{\mathrm{a}}$, Zihui Liang ${ }^{\mathrm{a}}$, Peilin Wang ${ }^{\mathrm{a}}$, Qiang $\mathrm{Ma}^{\mathrm{a} *}$, and Xingguang $\mathrm{Su}^{\mathrm{a} *}$

a Department of Analytical Chemistry, College of Chemistry, Jilin University, Changchun, 130012, China

Table of Contents for Supporting Information

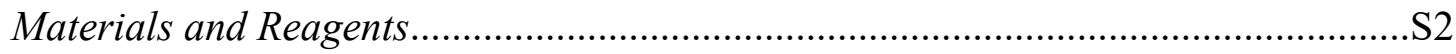

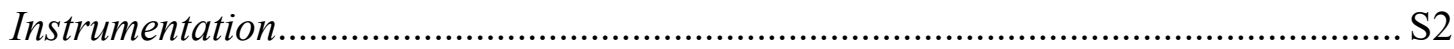

Synthesis of Au NBs, Au NRs and MnO NS@Probe DNA

S2

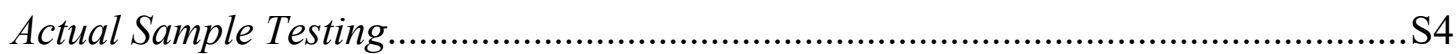

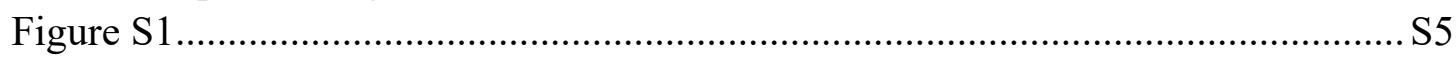

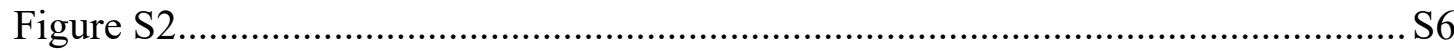

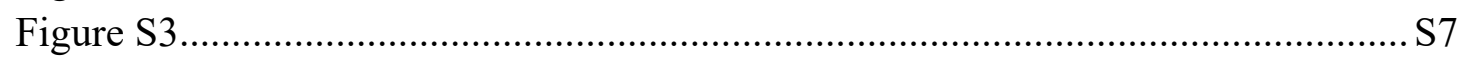

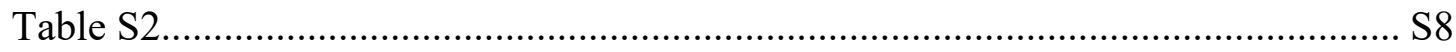

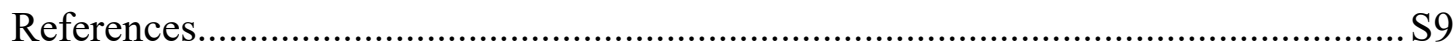




\section{Materials and Reagents}

All reagents were of analytical grade and required no additional purification. Titanium aluminum carbide, sodium hydroxide, TMAOH, CTAB, chloroauric acid, sodium borohydride, silver nitrate, benzyldimethylhexadecylammonium chloride (BDAC), ascorbic acid, sodium chloride, manganese chloride tetrahydrate, hydrogen peroxide, ethanol, APTES, carboxymethyl chitosan were purchased from Sinopharm Chemical Reagent Co., Ltd. The 1×TE buffer and T7 Exo with 10×NE buffer 4 were received from New England Biolabs. Synthetic oligodeoxy-nucleotides were purchased from Qingke Biotechnology Co., Ltd (Tianjin, China). All reagents were equipped with ultrapure water with a resistivity higher than $18 \mathrm{M} \Omega \mathrm{cm}^{-1}$. The nucleotide sequences of the oligonucleotides were list in the table below.

Table S1. The nucleotide sequences of the oligonucleotides in the work.

\begin{tabular}{|l|l|}
\hline \multicolumn{1}{|c|}{ name } & \multicolumn{1}{c|}{ sequences $\left(\mathbf{5}^{\prime} \mathbf{- 3}^{\prime} \mathbf{)}\right.$} \\
\hline miRNA-26a & UUCAAGUAAUCCAGGAUAGGCU \\
\hline Capture DNA & CCTGGATTACTTT-SH \\
\hline COOH-DNA & COOH-TATTATTATT \\
\hline Probe DNA & GTAATCCAGGTTAATAATAATA \\
\hline miRNA-126 & CAUUAUUACUUUUGGUAC \\
\hline miRNA-155 & UUAAUGCUAAUCGUGAUAGGGGU \\
\hline miRNA-221 & AGCUACAUUGUCUGCUGGGUU \\
\hline
\end{tabular}

\section{Instrumentation}

Transmission electron microscopy (TEM) images were accepted with JEM-2100F. Fourier transform infrared spectrometry (FT-IR) was acquired on a Thermo Nicolet 360 FTIR spectrometer with KBr pellets. All pH measurements were obtained with a PHS-3C pH meter (Tuopu Co., Hangzhou, China). A glassy carbon electrode (GCE) acted as the working electrode. A platinum wire and an $\mathrm{Ag} / \mathrm{AgCl}$ (saturated $\mathrm{KCl}$ ) electrode was used as the counter electrode and the reference electrode, respectively.

Synthesis of Au NBs and Au NRs. $0.5 \mathrm{~mL}$ of $1 \mathrm{mM}$ chloroauric acid solution and $1.5 \mathrm{~mL}$ of $0.2 \mathrm{M} \mathrm{CTAB}$ solution were mixed in $120 \mu \mathrm{L}$ of $0.01 \mathrm{M}$ ice-cold sodium 
borohydride solution. The brown solution was set aside for use. $1 \mathrm{~mL}$ of $4 \mathrm{mM}$ silver nitrate solution and $25 \mathrm{~mL}$ of $1 \mathrm{mM}$ chloroauric acid solution were mixed and poured into the mixture of $15 \mathrm{~mL}$ of $0.3 \mathrm{M}$ BDAC solution and $10 \mathrm{~mL}$ of $0.2 \mathrm{M} \mathrm{CTAB}$ solution to obtain the orange solution. When $0.3 \mathrm{~mL}$ of $0.1 \mathrm{M}$ ascorbic acid solution was dropped, the above mixture was gently stirred until the color faded. Finally, 50 $\mu \mathrm{L}$ of the previously prepared brown seed solution was added to the mixture. The red-purple capsule solution was sat undisturbed overnight and transformed into the $\mathrm{Au}$ NBs solution with the aid of $1 \mathrm{~mL}$ of $0.1 \mathrm{M}$ ascorbic acid solution. After centrifugation to remove the excess solvent, the Au NBs were prepared. ${ }^{1}$

$0.25 \mathrm{~mL}$ of $10 \mathrm{mM}$ chloroauric acid solution and $9.75 \mathrm{~mL}$ of $0.1 \mathrm{M}$ CTAB solution were quickly added in $0.6 \mathrm{~mL}$ of $10 \mathrm{mM}$ ice-cold sodium borohydride solution. The solution immediately became yellow-brown. After vigorous stirring for 10 minutes, the solution was kept stirring under room temperature for $1.5 \mathrm{~h}$. In order to prepare $\mathrm{Au}$ NRs, $0.1 \mathrm{~mL}$ of $10 \mathrm{mM}$ silver nitrate solution, $0.5 \mathrm{~mL}$ of $10 \mathrm{mM}$ chloroauric acid solution, and $9 \mathrm{~mL}$ of $0.1 \mathrm{M} \mathrm{CTAB}$ solution were mixed together. The solution was gently turned upside down. Then, $0.2 \mathrm{~mL}$ of $1 \mathrm{M} \mathrm{HCl}, 80 \mu \mathrm{L}$ of $0.1 \mathrm{M}$ ascorbic acid, and $1 \mathrm{~mL}$ of prepared seed solution were added into the above solution. The growth solution was turned upside down. Finally, the solution was allowed to stand under room temperature for $20 \mathrm{~h}$. Finally, it was purified by centrifugation at $16000 \mathrm{rpm}$ for 30 min. The Au NRs were prepared. ${ }^{2}$

Synthesis of $\mathrm{MnO}_{2}$ NSs@Probe DNA. $18 \mathrm{~mL}$ of $1.33 \mathrm{M}$ TMAOH solution and 10 $\mathrm{mL}$ of $0.3 \mathrm{M}$ manganese chloride tetrahydrate solution were prepared separately. $2 \mathrm{~mL}$ of hydrogen peroxide (30 wt\%) was added to the above TMAOH solution. The mixture was quickly poured into the manganese chloride tetrahydrate solution. The brown mixture was stirred at room temperature for one day and then washed with water and ethanol. $0.06 \mathrm{~g}$ of the manganese oxide nanosheets obtained, $330 \mu \mathrm{L}$ of APTES and $50 \mathrm{~mL}$ of ethanol were heated to $85{ }^{\circ} \mathrm{C}$ and refluxed for four hours. The $\mathrm{MnO}_{2} \mathrm{NSs}$ were washed by ethanol and dried for later use. ${ }^{3,4}$

As for $\mathrm{MnO}_{2} \mathrm{NSs} @$ probe DNA, COOH-DNA was activated by EDC and NHS (molar ratio $4: 1$ ) at $37^{\circ} \mathrm{C}$ for one hour. The activated COOH-DNA was incubated with 
$\mathrm{MnO}_{2} \mathrm{NSs}$ at room temperature and then washed. Probe DNA and $\mathrm{MnO}_{2}$ NS@COOH-DNA were incubated for two hours to obtain $\mathrm{MnO}_{2} \mathrm{NS} @$ probe DNA.

Actual Sample Testing. Blood collection tubes with inert separating gel and coagulant were used. After the specimen was centrifuged, the inert separating gel completely separated the serum and blood cells in the blood. The separated serum was stored at $-80^{\circ} \mathrm{C}$ for the further detection. 

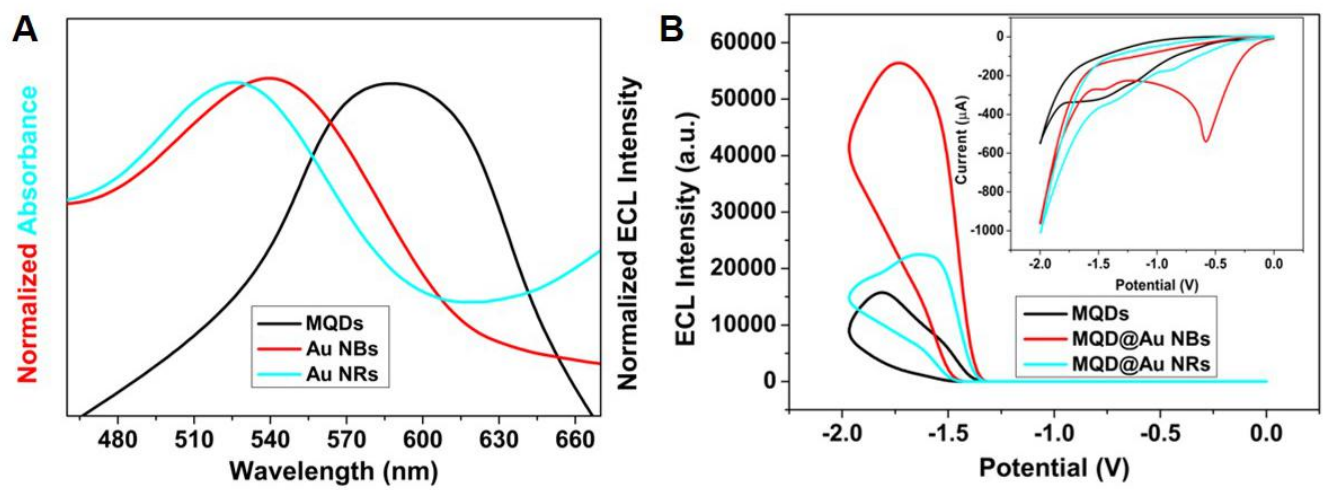

Figure S1. (A)The normalized ECL intensity of MQDs and the normalized absorption spectrum of $\mathrm{Au}$ NBs and $\mathrm{Au}$ NRs. (B) ECL-potential curves and cyclic voltammograms of MQD@Au NBs heterostructure and MQD@Au NRs heterostructure in PBS (pH 7.4) containing $25 \mathrm{mM} \mathrm{K}_{2} \mathrm{~S}_{2} \mathrm{O}_{8}$. 

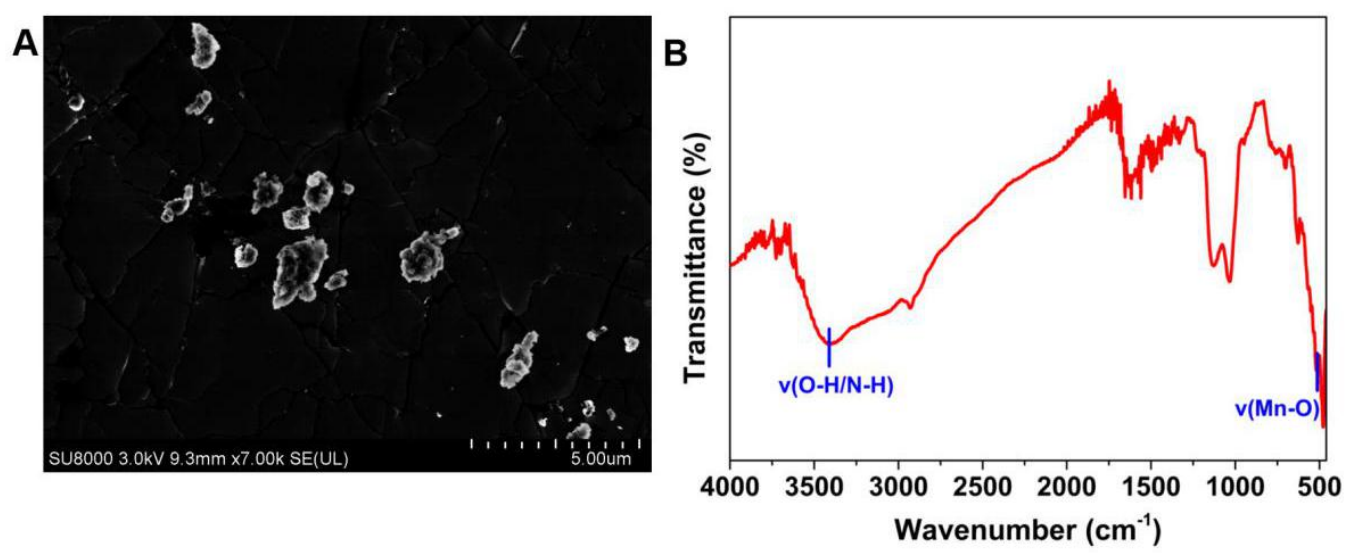

Figure S2. The SEM image (A) and FT-IR spectrum (B) of $\mathrm{MnO}_{2} \mathrm{NSs}$. 


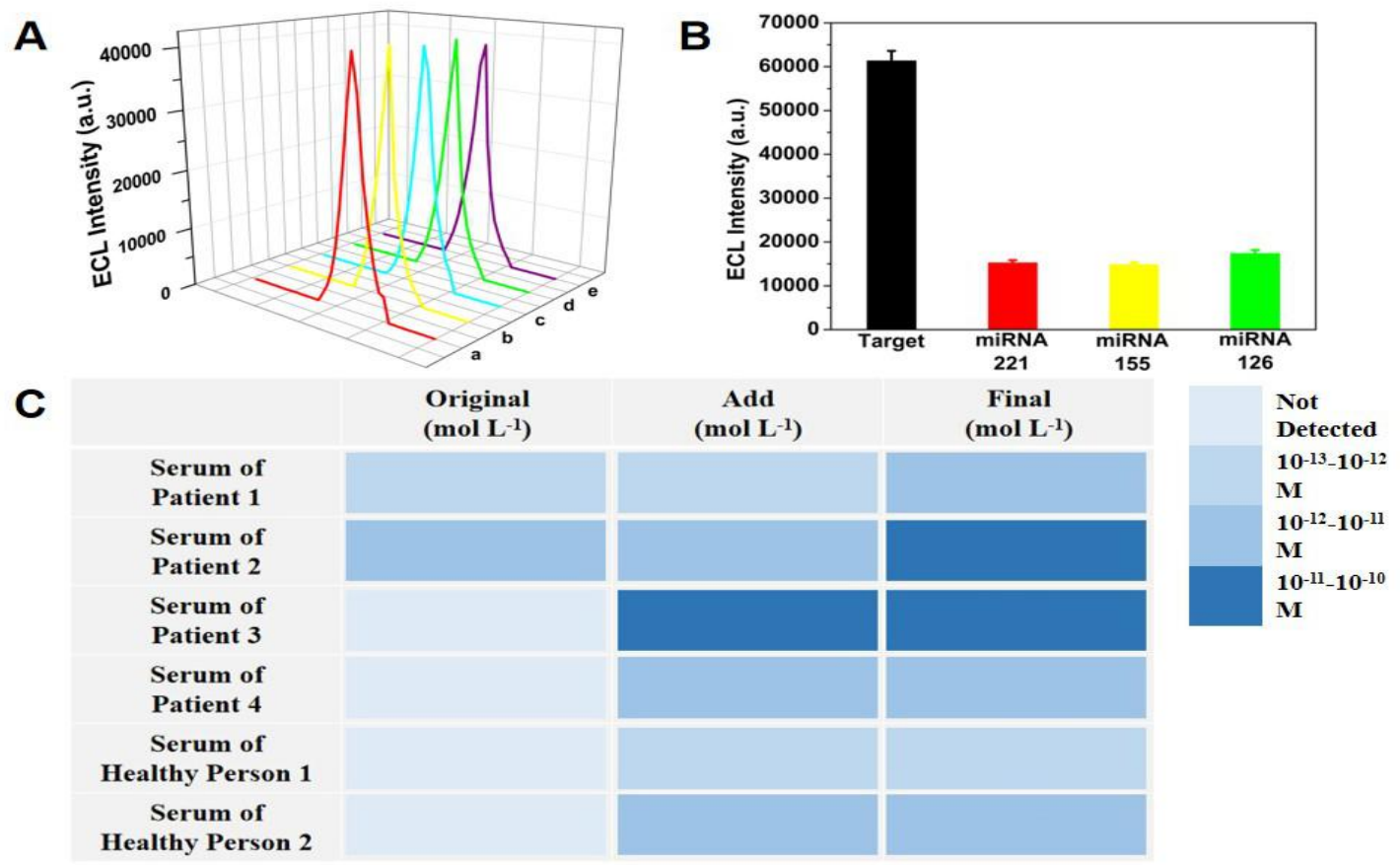

Figure S3. (A) The stability of sensors in different batches. (B) The effect of different miRNAs on ECL signals of proposed probe. (C) The test results of target miRNA-26a in clinical serum of patients and healthy people. 
Table S2. Comparison of other sensors of miRNA determination

\begin{tabular}{clll}
\hline Targat & Linear range & $\begin{array}{l}\text { Limit of } \\
\text { detection }\end{array}$ & Reference \\
\hline miRNA-26a & $0 \mathrm{nM}-500 \mathrm{nM}$ & $2.5 \mathrm{nM}$ & 5 \\
miRNA-26a & $5 \mathrm{fM}-5 \mathrm{pM}$ & $2.1 \mathrm{fM}$ & 6 \\
miRNA-221 & $0.1 \mathrm{nM}$ to $1 \mu \mathrm{M}$ & $38.3 \mathrm{pM}$ & 7 \\
miRNA-155 & $10 \mathrm{pM}$ to $10 \mathrm{nM}$ & $1.6 \mathrm{pM}$ & 8 \\
This work & $5 \mathrm{fM}-10 \mathrm{nM}$ & $1.7 \mathrm{fM}$ & This work \\
\hline
\end{tabular}




\section{References}

(1) Cifuentes-Rius, A.; Puig, H.; Kah, J.; Borros, S.; Hamad-Schifferli, K. Optimizing the Properties of the Protein Corona Surrounding Nanoparticles for Tuning Payload Release. ACS nano 2013, 7, 10066-10074.

(2) Chang, H.; Murphy, C. Mini Gold Nanorods with Tunable Plasmonic Peaks beyond $1000 \mathrm{~nm}$. Chem. Mater. 2018, 30, 1427-1435.

(3) He, D.; Yang, X.; He, X.; Wang, K.; Yang, X.; He, X.; Zou, Z. A sensitive turn-on fluorescent probe for intracellular imaging of glutathione using single-layer $\mathrm{MnO}_{2}$ nanosheet-quenched fluorescent carbon quantum dots. Chem. Commun. 2015, $51,14764-14767$.

(4) Zhao, K.; Liu, S.; Wu, Y.; Lv, K.; Yuan, H.; He, Z. Long Cycling Life Supercapacitors Electrode Materials: UltrathinManganese Dioxide Nanoscrolls Adhered to Graphene by Electrostatic Self-Assembly. Electrochim. Acta 2015, 174, $1234-1243$.

(5) Liao, R.; Li, S.; Wang, H.; Chen, C.; Chen, X.; Cai, C. Simultaneous detection of two hepatocellar carcinoma-related microRNAs using a clever single-labeled fluorescent probe. Anal. Chim. Acta 2017, 983, 181-188.

(6) Dong, H.; Zhang, J.; Ju, H.; Lu, H.; Wang, S.; Jin, S.; Hao, K.; Du, H.; Zhang, X. Highly Sensitive Multiple microRNA Detection Based on Fluorescence Quenching of Graphene Oxide and Isothermal Strand-Displacement Polymerase Reaction. Anal. Chem. 2012, 84, 10, 4587-4593.

(7) Ye, W.; Wei, Y.; Zhang, Y.; Yang, C.; Xu, Z. Multiplexed detection of micro-RNAs based on microfluidic multi-color fluorescence droplets. Anal. And. Bioanal. Chem. 2020, 412, 647-655.

(8) Zhang, Y.; Ma, C.; Ma, C.; Xiang, Y.; Mu, S.; Zheng, Z.; Liu, X.; Zhang, H. Ratiometric fluorescent detection and imaging of microRNA in living cells with manganese dioxide nanosheet-active DNAzyme. Talanta 2021, 233, 122518. 